\title{
On the Teaching and Learning of Fractions through a Conceptual Generalization Approach
}

\author{
Bojan Lazića, Sergei Abramovich ${ }^{b}$, Mirela Mrđaa and Daniel A. Romano \\ aUniversity of Novi Sad, SERBIA \\ bState University of New York, USA \\ 'IMVI, Banja Luka, BOSNIA AND HERZEGOVINA
}

\begin{abstract}
This paper deals with precursory (propaedeutic) learning of the concept of number in the elementary mathematical education. The authors' objective is to suggest a method allowing for the increase of the effectiveness of interactive expansion of the concept of number by using a gradeappropriate learning framework for elementary mathematical education content. A theoretical background for the creation of this method is based on the description of various characteristics of precursory learning and interactive teaching of mathematics as well and the flexible differentiation approach. The paper especially emphasizes the possibilities of propaedeutic understanding of the concept of fraction and examine the effects of such approach in terms of student achievement in elementary mathematics education, on the basis of a methodological approach. Results obtained during the experimental research suggest that under the influence of the methodological approach of introducing fractions through propaedeutic learning, students achieve significantly better results in learning compared to students who have not used this method.
\end{abstract}

\section{KEYWORDS}

Fractions · Propaedeutic learning $\cdot$ Methodological approach - Flexible differentiation - Empirical evaluation

\section{ARTICLE HISTORY}

Received 15 September 2016 Revised 03 July 2017 Accepted 30 October 2017

\section{Introduction}

This paper aims to contribute to research dealing with the teaching methods of continuing and interactive development of the concept of number, by implementing precursory learning within the framework of grade-appropriate teaching units. In the early age, children have an ability to form different

\section{CORRESPONDENCE Daniel A. Romano bato49@hotail.com}

(c) 2017 B. Lazić et al.

Open Access terms of the Creative Commons Attribution 4.0 International License apply. The license permits unrestricted use, distribution, and reproduction in any medium, on the condition that users give exact credit to the original author(s) and the source, provide a link to the Creative Commons license, and indicate if they made any changes. (http://creativecommons.org/licenses/by/4.0/) 
mathematical concepts in an informal way. During the process of developing their knowledge of the concept of number, many mathematical strands, most importantly, arithmetic and algebra are used. Because the concept of number is formed in a precursory (alternatively, propaedeutic) way in the preschool and in the lower grades of elementary school, it is not necessary to describe this process in detail. Didactic principles and conscious activities underlying the proposed teaching ideas will be of particular interest in this paper. In order to develop fundamental concepts in the elementary mathematics education (including the preschool), such as the concept of rational number, it is necessary to start early and maintain continuity throughout the entire duration of teaching activities. In order to have more efficient development the concept of number, connecting this process with learning operations of subtraction and division with the natural number set is of special importance.

The first expansion is based on by the fact that subtraction is a conditional operation because the equation $x+b=a$ has a solution only if $b<a$. In order to resolve the existence of a solution of the last equation for the cases $b=a$ and $b>a$, the set $N$ of natural numbers is expanded in the following way. In the first case, the number 0 is added to the set $N$ which then becomes the set $N \cup\{0\}$ (usually denoted $\boldsymbol{N}_{0}$ ). In the second case, the set $\boldsymbol{N}$ is augmented with so called set of negative integers, denoted $Z$ and defined $Z=\{-x: x \in N\}$. In that way, we also can determine the set of integers $Z$ as $Z=N_{0} \cup Z$.

A schoolteacher may define the procedure of division in $N$ through the binary relation 'is contained'. A natural number $m$ is contained in a natural number $n$ if and only if there exists a natural number $z$ such that $n=m \cdot z$, where the symbol '.' is the operation of multiplication in the semi-ring $\boldsymbol{N}$. Furthermore, a school teacher (almost always) rephrase this relation as follows: 'a natural number $n$ is divided by a natural number $m$ if there exists a natural number $z$ such that $n=m \cdot z$. Also, this procedure is often called 'divisibility in the set $N$ of natural numbers'. This procedure can be extended from the semi-ring $\boldsymbol{N}$ to the ring (a set closed under the binary operations of addition and multiplication) $\boldsymbol{Z}$ of integers. Consequently, a special procedure of division in the set $\boldsymbol{Z}$ of integers is enabled as follows: 'an integer $a$ is divided by integer $b(b \neq 0)$ if there exists an integer $z$ such that $a=b \cdot z$. This procedure is denoted by the symbol $b \mid a$. In this case, if the integer $z$ exists for the integers $a$ and $b$ the result is denoted $a \div b$ and called the quotient of a divided by $b$. The quotient $a \div b$ can be represented in the form of the fraction $\frac{a}{b}$ so that $\frac{a}{b}=a \div b$.

Given the above, we shall focus our attention in this paper on the methodological approach to propaedeutic content processing of fractions.

\section{Literature Review}

In the literature within the Research in Mathematics Education domain there is a significant number of publications devoted to the problem of teaching and learning fractions at the elementary level. Also, disciplined inquiries into mathematical practices of primary schools produced a large amount of information about students' difficulties in comprehending complex ideas about the concept of rational numbers. The value of this research is that knowing school practices does inform mathematics educators about the appropriate ways 
of resolving difficulties that students experience when learning to deal with fractions.

Learning fractions requires a reorganization of numerical knowledge, something that allows for a deeper understanding of numbers than it is ordinarily gained through experience with whole numbers (Charalambous \& Pitta-Pantazi 2005; Charalambous \& Pitta-Pantazi 2007; Siegler et al. 2011). Kieren (1976) was probably the first to propose that the concept of fractions consists of several sub-constructs and that understanding the general concept depends on gaining understanding of each of these different meanings of fractions as well as of their confluence. Kieren (1976) initially identified four sub-constructs of fractions: measure, ratio, quotient, and operator. These ideas were developed further (Behr et al. 1983; 1993; Kieren 1995), recommending that the part-whole relationship comprises a distinct sub-construct of fractions. This sub-construct was also connected with the process of partitioning.

Moving a step further, a theoretical model linking the above-mentioned different interpretations of fractions to the basic operations on fractions was developed and various theoretical models have been proposed for the learning and understanding of fractions.

For example, Strang (1990) argued that students' quite limited conceptual understanding of fractions is due to the reproductive teaching of mathematics through the mechanical repetition of various rules that a textbook provides. Whereas most of the students understand the formal symbolism of the fractional notation, they are unable to comprehend that different symbolic representations of fractions may be just alternative (equivalent) written forms of the same number. Likewise, confusion by students with the units of measurement (Amato, 2005) such as $\frac{m}{n}$ meters and $\frac{m}{n}$ kilometers can be observed through errors that they make when representing fractions in a numeric form (Hasegawa, 2000).

According to research findings (Charalambous \& Pitta-Pantazi 2007; Pitta-Pantazi et al. 2004) one of the factors that contributes to the marked complexity of learning and knowledge transfer is the introduction of multiple representations of fractions.

Mamede, Nunes \& Briant (2005) in their research focused on two basic models for fractions - the part-whole model and the dividend-divisor model. These authors explored how the two models play out in solving problems where the equivalent representation of fractions is used. Some publications, including Small (2009), Fosnot (2007), and Smith (2002), show that fractions as numbers used for expressing quantities represent the relationship between two integers, called numerator and denominator of a fraction, are understood in terms of the part-whole model. There is an agreement across all the publications mentioned above that whereas any part of a whole can be represented by a fraction, the latter has no meaning unless the whole is clearly identified.

Galen et al. (2008) emphasized that fractions play an important role in the development of mathematical thinking. Indeed, conceptually, fractions represent the critical part of the primary school mathematics curriculum and its natural extension into the domain of decimals and percentages. 
Hackenberg (2010) and Steffe \& Olive (2009) focused their research on issues of how students conceptualize fractional concepts, their relationship to whole numbers, multiplicative reasoning, and algebra. Also, these authors, by using examples of approaching problems in fractions including the schemes (Marshall 1993), construct the ideas about fractions through relating parts to a whole, producing a fraction as a multiple on a unit part, transforming a fraction into a commensurate fraction, or combining two fractions multiplicatively or additively.

In particular, some recent studies offering valuable methods of teaching and learning fractions and rational numbers will be highlighted.

Watanabe $(2006,2012)$ suggests that the focus of mathematics programs should be on fractions as quantity, allowing students to make a strong connection to their existing knowledge of whole numbers as quantities.

Lamon (2012) in particular, has emphasized the need for students to be introduced to a variety of fraction interpretations, stating that students whose instruction has concentrated on the part-whole fractions have an impoverished understanding of rational numbers.

Wittmann (2013), focusing on typical errors that students demonstrate when solving problems involving operations with fractions, argues that most of the errors are due to the inconsistency in the teaching methods that mathematical content of fractions requires. In turn, Prediger (2013) notes that although it is important to connect different models for fractions as a way of developing conceptual understanding of a fraction, establishing this connection is not the only means of effective instruction. Among other things, Prediger (2013) examined different strategies of connecting different models for fractions when the learning process is aimed at generating visual representations of fractions. An adequate application of the above didactic strategies was recommended as a comprehensive and structurally robust approach to the learning of fractions conceptually.

One of the results of the previous studies is that the existing methods have various limitations and inefficiencies, especially when the goal of mathematical instruction is to educate all students (Torbeyns et al. 2014).

Recently proposed integrated theory of numerical development (Siegler et al. 2011) suggests that the reason why learning fractions requires a reorganization of numerical knowledge is that children who have not learned fractions generally assume that the properties of whole numbers are the properties of all other numbers.

The following two distinctions are crucial for understanding developmental and individual differences in fraction knowledge:

- One distinction is between conceptual and procedural knowledge. Conceptual knowledge includes understanding of the properties of fractions: their magnitudes, principles, and notations. By contrast, procedural knowledge involves fluency with the four arithmetic operations.

- The other key distinction involves non-symbolic and symbolic knowledge. Non-symbolic knowledge involves competence with concrete stimuli...; symbolic 
knowledge involves competence with conventional representations (Siegler et al. 2013, p.14).

In the present paper, the authors pay special attention to the propaedeutic aspect of teaching fractions as described in (Santos 2008; Lazić et al. 2012; Lazić \& Maričić 2015). It is based on research carried out by one of the authors (Lazić 2015) during the preparation of his doctoral dissertation. The central part of the paper deals with the description of the method, which influences the increase of the efficiency of expanding the concept of a natural number as a way of teaching arithmetic of rational numbers through the application of propaedeutic learning.

\section{Theoretical Background}

\section{From examples to concepts as a learning trajectory}

In search of clear arguments and the methods to make the adoption of abstract mathematical concepts more familiar to students, one should pay special attention to the generally accepted view that any knowledge is built on prior knowledge (Berlin \& White 1995). This means that when we begin the early formation of fundamental mathematical concepts, it is most suitable to fit them into the course of previously initiated adoption of concepts or rules, to lay foundation for it on prior student knowledge, whether they were acquired in the prior process of learning, or based on the child's experience (Lazić \& Maričić 2015). Anyway, early initiation of learning must be understood as preparatory, precursory, introductory or propaedeutically teaching and learning (comes from the Greek word 'propaideuo').

Conceptualization introduces clarity and structure into the world of real and reflective objects. According to most of the authors, by conceptually summing up similar objects and phenomena into one category, we can affect this entire category in the same way, and in individual cases only apply them. In that respect, concepts are a basis for every cognitive functioning, because by adequately simplifying the world, they standardize it and make it transferable. This applies to the real world as well as to the world of science and especially, mathematics. Rational number sense can be built from students' understanding of whole number. When students utilize the same decomposing strategies and understanding of the partitioning and grouping of whole numbers, their rational number sense increases. In order for the fraction sense to be acquired, there are three foundational concepts to be taken into consideration: conceptual understanding and procedural knowledge, cognitive theories, and instructional methods.

The term concept typically refers to a common characteristic of a set of objects that can be described or defined as a combination of several attributes. From the psychological standpoint, an important fact is that a concept can be formed as one mental unit within a cognitive structure without even knowing the exact definition or terminological guidelines. The linguistic form and structure determining the concept of number, under certain conditions, by using clear limitations within the framework of the cognitive structure, can significantly facilitate one's thinking and communication about this concept. For example, the first decade forms the terminological definition and the verbal definition defines it as a set of numbers1, 2, 3, 4, 6, 7, 8, 9 and 10. However this 
does not form the concept of numbers of the first decade aligned with axiomaticset approach, which requires much more time.

The learning of concepts begins with specific examples from which a pupil can later decontextualize. Inductive formation of concepts gradually turns into deductive formation through a verbal (written) definition supported by examples. The formation of basic concepts is mostly applied to the teaching at the early elementary level and it is based on the use of many examples and counterexamples de-emphasizing mathematical formalism and exact verbalization. Indeed, "concepts are most effectively formed through a combination of examples, counterexamples and verbal explanations" (Tennyson \& Park 1980, p. 56).

Interaction implies an interactive relationship and active communication among pupils, teachers and parents. The majority of pupils enjoy interaction during their learning process. Having in mind that a pupil receives assistance only when he or she needs it (the principle of minimal assistance), this form of learning and teaching is called flexible differentiation (Rasmussen 2004; Petrovic et al. 2011). As Mrdja et al. (2015) noted "If a pupil is cognitively active in the period between being instructed and given feedback, regardless of the result of the activity, he or she is interacting" (p. 90). Flexible differentiation is a part of what Abramovich, Easton \& Hayes (2012) called Style II assistance - a way of teaching enabling the stability of pupils, presence at the deep structure of learning (Shulman, 2005) and supporting their intellectual curiosity within the zone of proximal development (Vygotsky 1987).

In mathematics education for junior grades of the primary school, curriculum content, i.e. teaching topics and units can be introduced through complete processing, or propaedeutically (Gleizer 1997; Klippert 2001; Milinković 2007; Lazić et al. 2012; Vasilyev \& Gromyko 2015). Through propaedeutic learning in elementary mathematics education, students are introduced to the contents that enable them to independently and actively participate in life situations at the right time. It is believed that knowledge acquired this way is rationalized and facilitate a continued study of mathematics, especially in those contents that have been propaedeutically processed. In addition, this method of learning could achieve a more "painless" and more efficient approach to learning mathematics in senior grades of the primary school.

However, the practice shows that propaedeutic processing in elementary mathematics education, especially in junior grades of the primary school, although very significant, is insufficiently represented (Lazić 2015). The aforementioned practice is a consequence of the inertia in the educational systems and slow acceptance of drastic changes, especially in the field of methodological approach to the fundamental contents. And propaedeutic education is exactly what provides the necessary introductory knowledge and prevents difficulties in adopting mathematical content at higher levels of primary education.

That is why the authors believe that the proposed methodology of the early preparation to the learning of the broad content of fractions through the propaedeutic approach is fully justified. 


\section{A Method of Teaching and Learning}

\section{Motivating negative numbers}

Because within a number of educational systems the transition from natural numbers to integers occurs relatively late in the school mathematics curriculum, the authors suggest an alternative way of developing the concept of negative number through the propaedeutic approach. For that purpose, we use tasks which can be incorporated in the teaching and learning of subtraction of natural numbers. In this paper we state one example from the real context suitable for second-grade pupils.

\section{Example 1}

A child had $\$ 85$ in his piggy bank. He thought it was enough money to buy a bicycle. However, the bicycle which he liked costs\$93. He calculated the amount of money he was missing and borrowed that amount from a friend.

(1) How did the child calculate the missing amount? $(93-85=8)$

(2) If the measuring number of his debt is referred to as a minus and is marked with the symbol ,-“, write that number down in words and through a mathematical symbol (in words: minus eight, mathematically: -8)

(3) On the number line, mark the dot which represents the child's debt after buying the bicycle.

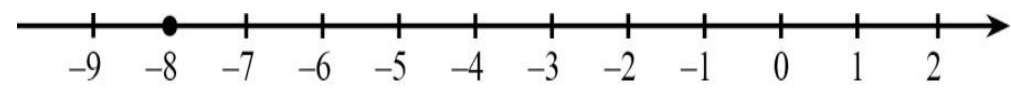

Fig. 1 Display of the number -8

\section{Quotient as a fraction}

We focus our attention in this paper to the methodological approach to propaedeutic content processing of positive rational numbers. For that purpose, we will list the basic elements of the methodological approach on an example of forming the concept of fractions in elementary mathematics education.

In the initial learning of mathematics, the pupils first understand a fraction as a part of the unity provided that all parts of the unity are mutually equal and that the number of parts is an integer. Such a fraction is called a unit fraction. It is possible to understand the concept of unit fraction in a propaedeutic way at that age and to show it on the number line as a part of an equation for straight lines, for basic fractions. The most suitable teaching units for that are the ones that teach rules of division, that is, the determination of the quotient. It means that in the third grade at the latest (9 to 10 years of age), the equivalence of a mathematical symbol for a fraction and for a quotient is introduced; that is, the indicated quotient $a \div b$ has the same meaning and value 
as the fraction $\frac{a}{b}$. The role of the dividend in the quotient is thereby the same as the role of the numerator in a fraction, as well as the role of the divisor in the quotient is the same as the role of the denominator in a fraction.

By applying the rule of change of quotient depending on the change of numerator, we can complement the formation of the concept of a positive fraction $\frac{a}{b}$. In other words, the property if the dividend increases by a certain number of times then the quotient increases by the same number of times is equivalent to the property if the numerator increases by a certain number of times then the fraction increases by the same number of times. According to these properties, the equalities follow: $\frac{a}{b}=a \div b=(a \cdot 1) \div b=a \cdot(1 \div b)=a \cdot \frac{1}{b}$. For example, the fraction $\frac{3}{4}$ is understood as three times the unit fraction $\frac{1}{4}$, that is $\frac{3}{4}=3 \cdot \frac{1}{4}$ and it can be used as an exemplar.

The final formation of the concept of real numbers, as a category of equivalence of equal fractions, is possible only after the interactive processing of the teaching unit Expansion and Reduction of Fractions (11 to 12 year-old pupils). With regard to all of the above, the preparation for processing of this teaching unit is hereby displayed in full. For interactive processing of this teaching unit, we use the structure of a class described by Lazic et al. (2012).

\section{Preparation stage}

Interactive revision of the pupils' previous knowledge, which is directly related to the processing of the contents planned for the operative stage.

\section{Operative stage}

- An exemplar (example or a set of examples) is determined.

- After that pupils engage in thinking activities (observation, comparison with elements of analysis and synthesis), they notice important elements for the formation of the concept or adoption of the rules. Pupils perform these activities with the teacher's differentiated assistance. Differentiated assistance means that a student uses parts of the instructions - only those that are needed (Zech 1999, Shulman 2005, Abramovich et al. 2012). After that, with the teacher's guidance pupils analyze framed texts which determine the concept or the rules. Thereby, pupils perform generalization which requires the engagement in a thinking process such as abstraction.

- By making new examples the pupils confirm, unite and broaden the textual determination of the concept or the adoption of rules.

\section{Verification stage}

Verification summary is directed to the processing of exemplars (solving problems) and part of ready-made examples (1-2) for confirmation, broadening and unification. After that, homework is assigned. 


\section{A Description of Interactive Processing of the Teaching Unit Developing the notion of equivalent fractions}

In the preparation stage, the teacher emphasizes interactive revision of knowledge acquired during the processing of a teaching unit, especially the propaedeutic part of it. To begin, we have to describe how the partition of a circle into thirds, sixths, ninths, and twelfths is carried out

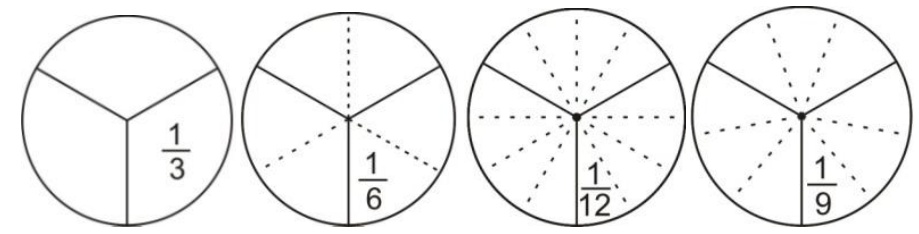

Fig. 2 Partition of a circle into thirds, sixths, ninths and twelves

As shown in Figure 2, we can divide a circle into three equal parts, each of which is $\frac{1}{3}$ and then divide each $\frac{1}{3}$ into two equal parts, each of which becomes $\frac{1}{6}$ (because six of such parts make the whole). Then each $\frac{1}{6}$ is divided into two equal parts each of which becomes $\frac{1}{12}$ (because 12 of such parts make the whole). Finally, each $\frac{1}{3}$ is divided into 3 equal parts each of which becomes $\frac{1}{9}$ (because 9 such parts make the whole).

The diagram of Figure 3 is used as a didactic material needed for the processing of the first part of the exemplar in the operative stage. With teacher's guidance, the pupils notice, conclude, and write down the following sentences in their notebooks.

The circle (unity) is divided into equal parts: thirds, sixths, ninths and twelfths. Similarly, the shaded parts of the circles correspond to (or represented by) the fractions: $\frac{2}{3}, \frac{4}{6}, \frac{6}{9}$ and $\frac{8}{12}$.

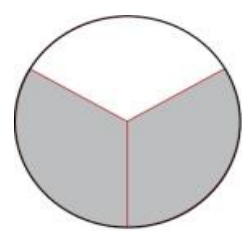

$\frac{2}{3}$

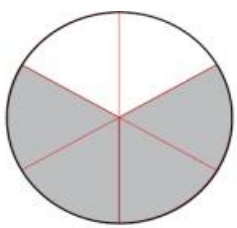

$\frac{4}{6}$

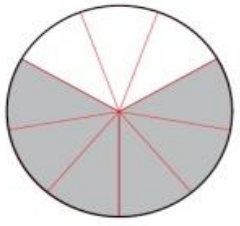

$\frac{6}{9}$

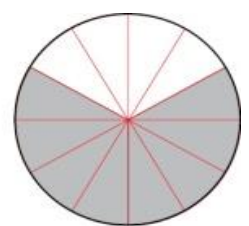

$\frac{8}{12}$

Fig. 3 Application for processing the first part of the exemplar 
So, that we can conclude that $\frac{2}{3}=\frac{4}{6}=\frac{6}{9}=\frac{8}{12}$ is valid (Figure3). The pupils, thereby, notice that the numerator is $4=2 \times 2$ and the denominator is $6=3 \times 2$ (doubled), numerator is $6=3 \times 2$ and the denominator is $9=3 \times 3$ (tripled), numerator is $8=2 \times 4$ and denominator is $12=3 \times 4$ (quadrupled).

For the other part of the exemplar we use

Example 2.

A child ate half of a chocolate bar divided into 24 equal pieces. The model of the chocolate bar is displayed in Figure 4.

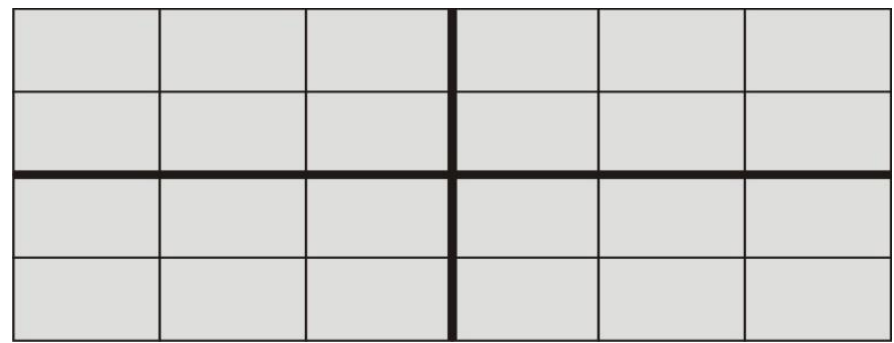

Fig. 4 Application for processing the other part of the exemplar

The half of the chocolate can be described in different ways. The task is to, fill in the gaps in notations for fractions:

(1) If the chocolate were broken along one of the bold lines, the eaten part should be represented by the fraction $\frac{-}{2}$.

(2) If the chocolate were broken along the straight lines parallel to the larger sides of the rectangle, the eaten part should be represented by the fraction $\frac{2}{2}=\frac{1}{2}$.

(3) If the chocolate were broken along the straight lines parallel to the smaller sides of the rectangle, the eaten part should be represented by the fraction $\frac{1}{6}=\frac{1}{2 \cdot}$.

(4) If the chocolate were broken piece by piece, the eaten part should be represented by the fraction $\frac{12}{2}=\frac{1 \cdot}{2}$.

\section{From arithmetic to algebra}

Based on the picture (Figure 5) and teacher's guidance, pupils move to generalization. The given rectangle (unity) is divided into $b$ equal parts, using 
straight lines parallel to the smaller sides, and we thereby colored a equal rectangles. Then we divided the rectangle into $k$ equal rectangles using straight lines parallel to the larger sides.

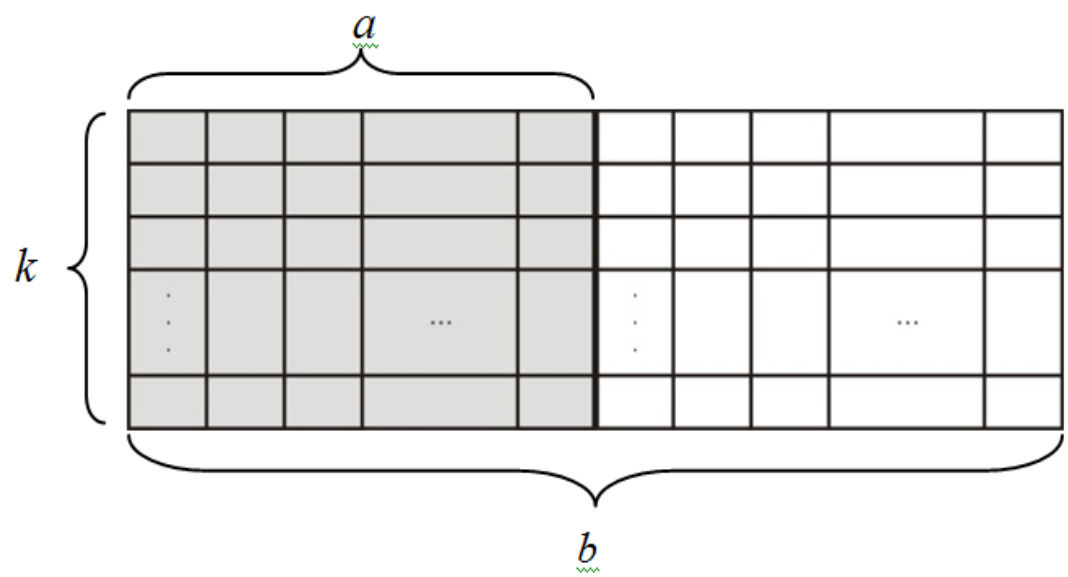

Fig. 5 Application for generalization of the rules for expansion and reduction

The intersection of the drawn $b$ and $k$ rectangles comprise $b \cdot k$ squares serving as a common measure of each of the rectangles (equal parts of the unity), and their shaded part comprise $a \cdot k$ such squares. From the previously stated we can conclude that the shaded part of the rectangle (unity) is represented by the fractions $\frac{a}{b}$ and $\frac{a \cdot k}{b \cdot k}$. Because the last two fractions represent the same part of the unity, they may be considered equal, in other words, the equality

$$
\frac{a}{b}=\frac{a \cdot k}{b \cdot k}
$$

holds true.

Equality (1) could also be demonstrated through the change of unit. For example, the top diagram of Figure 6 represents $\frac{a}{b}$ through the circles. Let $k$ be an integer, so that $a k$ and $b k$ are represented by the next two diagrams of Figure 6 , also through the circles. Grouping $a k$ and $b k$ as shown at the bottom diagram of Figure 6 to form a new unit, a rectangle, shows that a rectangle replaces a circle as a unit so that equality (1) is satisfied.

By using the above models, equality (1) was developed under the condition $a<b$. Likewise, equality (1) can be demonstrated to be true in the case $a \geq b$. It means that equality (1) holds true for any three natural numbers $a, b$ and $k$. This conclusion can be interpreted and written down by pupils in the following two ways.

(1) Given the fraction $\frac{a}{b}$, its value does not change when the numerator and the denominator are multiplied by the same number. We can say that the 
fraction $\frac{a}{b}$ is expanded by the number $k$, and the procedure is called the expansion of the fraction to an equivalent form.

(2) If the given fraction is $\frac{a \cdot k}{b \cdot k}$, in other words, there is a common factor $k$ in the numerator and the denominator, the value of the fraction does not change if we cancel out the common factor. We can say that the fraction $\frac{a \cdot k}{b \cdot k}$ is reduced by the number $k$, and the procedure is called the reduction of the fraction to a simpler form.

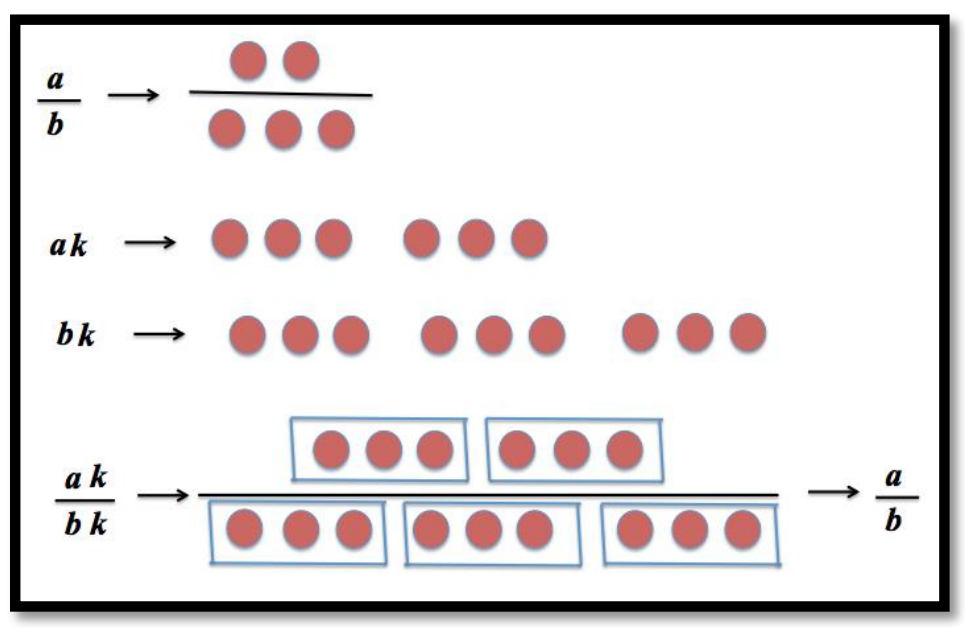

Fig. 6 Reduction of a fraction as a change of unit

At the end of the operative stage, the teacher reminds the pupils about a procedure for determining $G C D(a, b)$ : We noticed that procedure ends when we write relatively prime numbers $c$ and $d$ in place of $a$ and $b$. It means that for natural numbers $a$ and $b$ there exist relatively prime numbers $c$ and $d$, so that $a=c \cdot G C D(a, b)$ and $b=d \cdot G C D(a, b)$.

From the above, it follows that $\frac{a}{b}=\frac{c \cdot G C D(a, b)}{d \cdot G C D(a, b)}=\frac{c}{d}$, and the fraction $\frac{c}{d}$ cannot be further reduced.

We say that the fraction $\frac{a}{b}$ is reduced to the simplest form, $\frac{c}{d}$, and the fraction $\frac{c}{d}$ cannot be reduced or, is irreducible. If not pointed out otherwise, when we reduce a fraction we are not abbreviated it all the way. It means that reduction is completed when we reach an irreducible fraction equal to the given fraction. In that way, the infinite set of equal fractions is represented by one, irreducible fraction, which is a positive rational number. On the number line, using one dot, we represent it with any positive rational number $\frac{c}{d}$, which is 
equivalent to an infinite number of equal fractions. For visual illustration, on the number line (Figure 7 ) we display rational numbers $\frac{2}{3}, \frac{1}{2}$ and $\frac{c}{d}$.

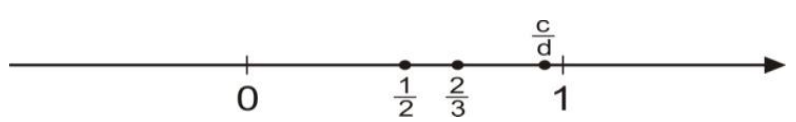

Fig. 7 Display of the numbers $\frac{2}{3}, \frac{1}{2}$ and $\frac{c}{d}$

In the verification stage, besides the interactive summary, the pupils start solving the tasks which they will finish as at homework.

Reduce the fractions to the simplest form and display them on the number line: (a) $\frac{1485}{1585}$, (b) $\frac{2296}{1092}$.

In that way, as "new concepts come through the shift of old concepts to new situations" (Schon, 1963, p. 53), we complete the precursory expansion of the concept of number to the set of rational numbers $Q$.

We introduce other contents in a similar way, propaedeutically. Based on the created methodological approach, the basis of which is the expansion of a natural number through propaedeutic understanding of the fraction as a positive rational number, we organized a research to examine its effects in terms of student knowledge adoption in elementary mathematics education.

\section{Description of the Empirical Evaluation of the Method}

Empirical research was conducted on a sample of pupils $(\mathrm{N}=240)$ which was selected from the population of fourth graders from elementary schools in Novi Sad and Sombor, Serbia. The described method was the basis for the work conducted in the experimental group in the empirical part of this research. Besides the described models, pupils from the experimental group learned relations between fractions with equal numerators or denominators, addition and subtractions of fractions with equal denominators, and the multiplication of a fraction by a natural number in the propaedeutic way as described in this paper. For statistical processing of the data Microsoft Excel and statistical package Statistica 12 (StarSoft Inc., Tulsa, OK, USA), university license of the University of Novi Sad, was used. While editing the results, compliance with normal distribution was tested using the Kolmogorov-Smirnov test. In the case of the normal distribution the t-test was used; in the case when the distribution diverged from the normal the Man-Whitney $U$ test was used. The differences when $p<0.05$ were considered statistically relevant.

For the purposes of examining the effect of the conceptual generalization approach on the increase of the effectiveness of the interactive expansion of the concept of number as well as for the prevention of failure and rationalization of learning at the higher levels of mathematical education, two final tests were administered within the same sample of pupils. The first test was given to fifth graders, after the end of the experimental program in the fourth grade. The second test was given to fifth graders after processing the content of rational numbers. The second test measured the following abilities of the pupils: 
durability of knowledge, independent problem solving, the implementation of the acquired knowledge in real-life contexts, and the pupils' general knowledge of positive rational numbers.

Table 1 Mean value achievement of the pupils of experimental and control groups in all three tests

\begin{tabular}{|c|c|c|c|c|c|c|}
\hline & \multicolumn{2}{|c|}{ Experimental group } & \multicolumn{2}{|c|}{ Control group } & \multirow[b]{2}{*}{$T$-value } & \multirow[b]{2}{*}{$p$-value } \\
\hline & Mean val. & Stand. Dev. & Mean val. & Stand. Dev. & & \\
\hline Initial test & 26.37143 & 12.39468 & 25.72857 & 11.84431 & .31373 & .754202 \\
\hline I Final & 37.37143 & 12.12874 & 23.28571 & 12.10838 & 6.87641 & .00 \\
\hline II Final & 41.97143 & 8.96365 & 20.95714 & 10.15594 & 12.97948 & .00 \\
\hline
\end{tabular}

As one can notice from Table 1 , based on the calculated values of $t$ (6.88; $12.98)$ and $p(p<0.05)$ at the level of relevance of 0.05 , it was found that there are significant statistical differences on both final tests in achievements of pupils who learned fractions in different ways in the fourth grade. The experimental group has achieved significant statistical progress, while the control group demonstrated a decline in the results compared to the initial testing. The greatest progress of the pupils from the experimental group was achieved over time, on the second final test. By comparing the results of the second test and the first test, a statistically significant difference in pupils' progress over time was recorded. At the same time, the pupils from the control group, compared to the initial measuring, demonstrated the greatest decline in results.

The specified significant differences in achievements of groups of pupils experimental and control are illustrated in the graph of Figure 8. 


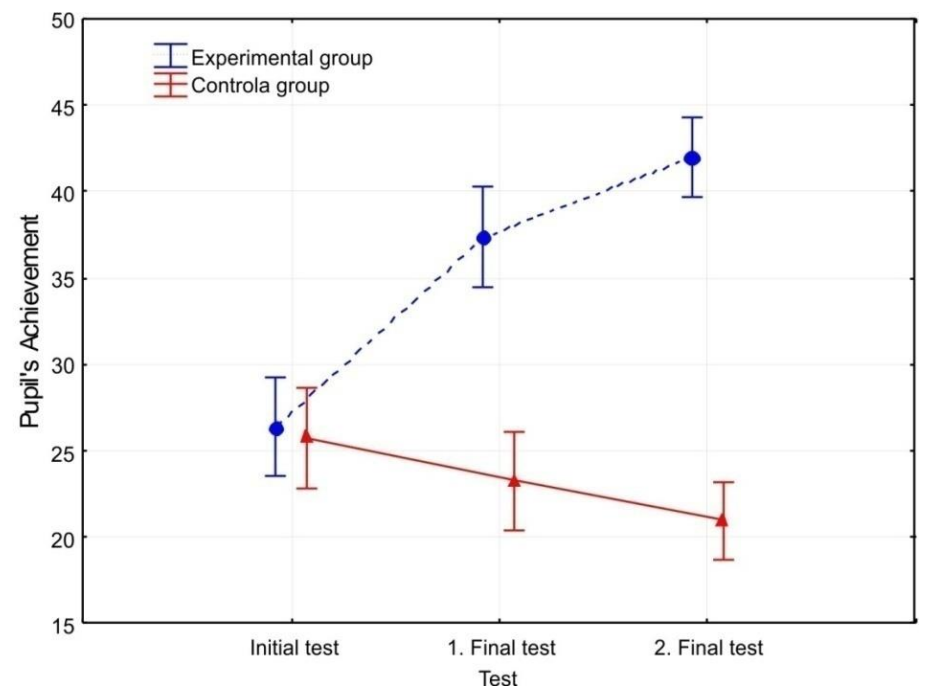

Fig. 8 Graphic display of comparison of the results in groups experimental and control on all three tests

The inverse relation between the results of both groups regarding to time is obvious. While the results of the experimental and the control groups in the initial measuring are approximately the same, the values of the achievements in the experimental group on both final measurements are significantly greater and the difference of the results is smaller compared to the control group.

Along with significant achievement in overall learning, the pupils in the experimental group demonstrated considerably greater achievements in all individual abilities that were studied. The results show a positive effect on learning of the conceptual generalization approach, which primarily refers to the increase of the durability of knowledge, the ability to independently solve problem tasks, and the ability to implement the acquired knowledge in real-life context. The results according to the specified effects examined in this study are illustrated in the graph of Figure 9.

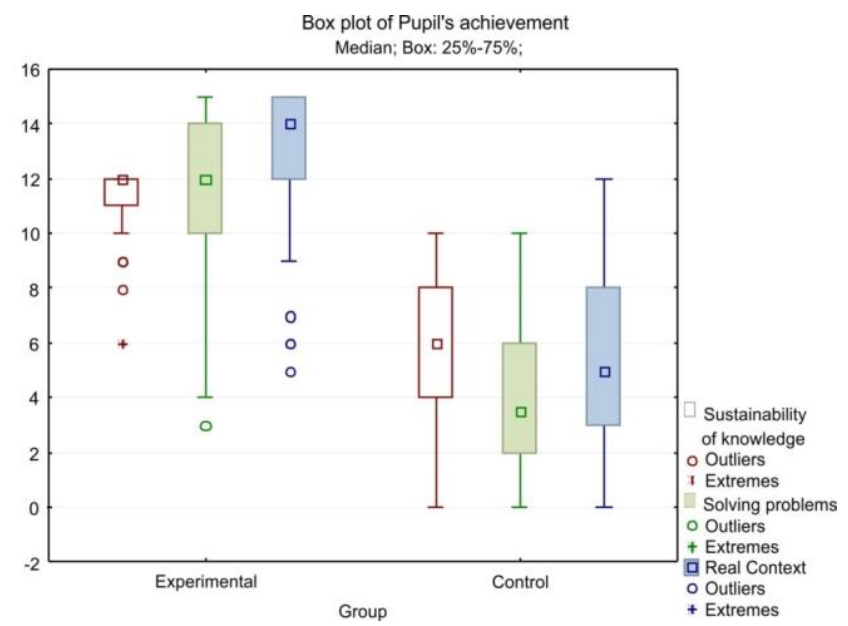


Fig. 9 Representation of pupil's achievement for the three groups of tasks: Sustainability of knowledge, Solving problems and Real context

In addition to the specified benefits, the positive effect of learning mathematical contents through the conceptual generalization approach also deals with the increase of interest, motivation, and on-task behavior among the pupils (Figure 10). The statement "I would like for our teacher to continue to teach this way", is accepted with a scale index value of 2.87 , in other words, the majority of pupils, 62 (or $88.57 \%$ ), agreed with this statement.

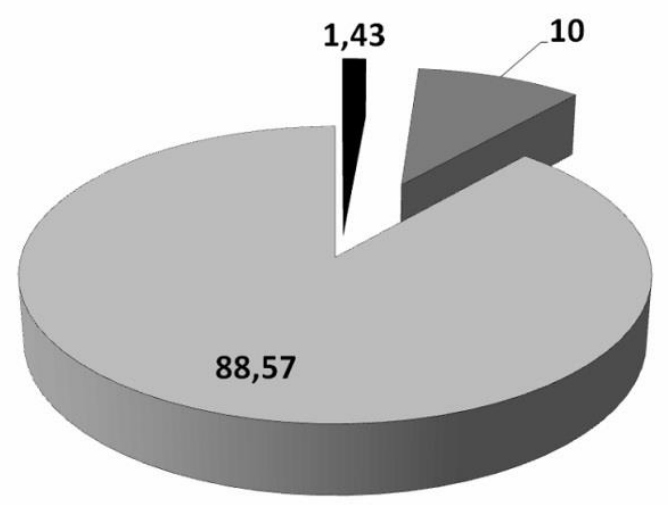

No I do not agree $\quad \square$ I do not know, I am not sure $\quad \square$ Yes, I agree

Fig. 10 Diagram showing the level of agreement of pupils in experimental group with the given statement

It appears that the pupils, working according to the method described in this paper beginning with grade one, would achieve even better results. With the implementation of our approach in the teaching practice of the elementary education, we expect an increase in the effectiveness of learning mathematical contents as well as their implementation in teaching of mathematics and other school subjects.

\section{Conclusion}

This paper was concerned with theoretical and practical aspects of interactive development of the concept of number in the primary school, based on the conceptual generalization approach. Teaching and learning was considered within the framework of the teaching contents suitable for younger pupils (ages 7-11 years old). The paper examined a number of commonly accepted theoretical frameworks and discussed current research on the learning of fractions. In this paper, we draw attention to the role and importance of propaedeutic learning/education in the process of forming mathematical concepts, in elementary mathematics education. We presented a methodological approach based on the expansion of the concept of the natural number through propaedeutic understanding of the fraction as a positive rational number, and then displayed results of the research. 
The first step was made, within the framework of contents about subtraction by forming the concept of a negative integer in a propaedeutic way. Then we connected the corresponding contents about the operation of division with the optimally possible level of the preliminary formation of the concept of a positive rational number. The final stage of the formation of the concept of a rational number was manifested through the description of the interactive teaching of the unit Expansion and Reduction of Fractions. Using the given methodological framework and the models of the corresponding teaching units (Lazić 2015), both teaching and learning was carried out within the experimental group.

By analyzing the classes taught and statistically processing the data collected, it has been found that the process of expanding the concept of number through the implementation of the precursory learning grounded in the conceptual generalization approach was successfully accomplished. Propaedeutic introduction of fractions to students greatly affects the efficiency of their learning of these contents during education. Therefore, the structure and the content of classes are fully coordinated with didactic principles, especially those of conscious activity and rationalization. By implementing contemporary didactic systems, teaching methods, and improved motivational techniques, significantly better learning outcomes were achieved by the pupils. The increase in interest and level of attention among the pupils in parts of the class reserved for introductory processing confirms the stated characteristics and the significance of propaedeutic teaching.

\section{Disclosure statement}

No potential conflict of interest was reported by the authors.

\section{Notes on contributors}

Bojan Lazić - Faculty of Education in Sombor, University of Novi Sad, Serbia

Sergei Abramovich - State University of New York, Potsdam, USA

Mirela Mrđa - Faculty of Education in Sombor, University of Novi Sad, Serbia

Daniel A. Romano - IMVI, Banja Luka, Bosnia and Herzegovina

\section{References}

Abramovich, S., Easton, J. \& Hayes, V.O. (2012). Parallel structures of computer - assisted signature pedagogy: the case of integrated spreadsheets, Computers in the Schools, 29(1-2), 174-190.

Amato, S. A. (2005). Developing students'understanding of the concept of fractions as numbers. In H. L. Chick \& J. L. Vincent (Eds.), Proceedings of the 29th PME International Conference, 2, 49-56.

Behr, M., Lesh, R., Post, T. \& Silver, E. (1983). Rational Number Concepts. In R. Lesh \& M. Landau (Eds.), Acquisition of Mathematics Concepts and Processes, (pp. 91-125). New York: Academic Press.

Behr, M., Harel, G., Post, T. \& Lesh, R. (1993). Rational Numbers: Toward a Semantic Analysis-Emphasis on the Operator Construct. In T. P. Carpenter, E. Fennema, \& T.A. Romberg, (Eds.), Rational Numbers: An Integration of Research (pp. 13-47). NJ: Lawrence Erlbaum.

Berlin, D. F. \& White, A. L. (1995). „Connecting School Science and Mathematics”. In: Connecting Mathematics across the Curriculum, Ed. House, P. A. \& Coxford, A. F., National Council of Teachers of Mathematics, 1995. Yearbook, Reston, Virginia. 
Charalambous, C.Y. \& Pitta-Pantazi, D. (2005), Revisiting a theoretical model on fractions: Implications for teaching and researching, In Chick, H. L. \& Vincent, J. L. (Eds.). Proceedings of the 29th Conference of the International Group for the Psychology of Mathematics Education, (Vol. 2, pp. 233-240), Melbourne: PME.

Charalambous, C.Y. \& Pitta-Pantazi, D. (2007), Drawing on a theoretical model to study students' understanding of fractions, Educational Studies in Mathematics, 64(3): 293-316.

Fosnot, C. (2007). Field Trips and Fund Raisers: Introducing Fractions. Portsmouth: Heineman.

Galen, F., Feijs, E., Figueiredo, N., Gravemeijer, K., Herpen, E. \& Keijzer, R. (2008). Fractions, percentages, decimals and proportions: A learning-teaching trajectory for grade 4, 5 and 6. Rotterdam: Sense.

Gleizer, D. G. (1997). Geometry in the school: problems and judgments. Norma, 3 (1-2), 9-20.

Hackenberg, A.J. (2010). Students' reasoning with reversible multiplicative relationships. Cognition and Instruction, 28(4), 383-342.

Hasegawa, J. (2000). Classroom discussion on the representation of quantity by fractions: Stability of misconcepuon and implications to practice. In T. Nakahara \& M. Koyama (Eds.). Proceedings of the 24th PME International Conference, 3, 41-48.

Kieren, T.E. (1976). On the mathematical, cognitive, and instructional foundations of rational numbers. In R. Lesh (Ed.), Number and Measurement: Papers from a Research Workshop (pp. 101-144). Columbus, OH: ERIC/SMEAC.

Kieren, T.E. (1995), Creating Spaces for Learning Fractions. In: J. T. Sowder \& B. P. Schappelle (Eds.), Providing a Foundation for Teaching Mathematics in the Middle Grades, (pp. 31-66). Albany: State University of New York Press.

Klippert, H. (2001). How to successfully teach the team. Zagreb: Eduka.

Lamon, S.J. (2012). Teaching Fractions and Ratios for Understanding: Essential Content Knowledge and Instructional Strategies for Teachers. New York, NY and London, UK. Routledge.

Lazić, B. (2015). Propaedeutic Introduction of Fractions in Arithmetics for Lower Grades of Primary School, Ph.D. Thesis, University of Belgrade, Teaching Training Faculty.

Lazić, B. \& Maričić, S. (2015). Propaedeutic formation of the concept of fraction in elementary mathematics education; In: Novotná, J. \& Moraová, H. (Eds.), Proceedings if Developing Mathematical Language and Reasoning, (pp. 212-221), Charles University, Faculty of Education, Prague.

Lazić, B., Milinković, J. \& Petojević, A. (2012). Connecting mathematics in propaedeutic exploration of the concept of fraction in elementary grades, In: Brankovic, N. (Ed.), Theory and Practice of Connecting and Integrating in Teaching and Learning Process (pp. 123-137). Sombor: Faculty of Education in Sombor.

Mamede, E., Nunes, T. \& Bryant, P. (2005). The equivalence and ordering of fractions in part-whole and quotient situations. In H. L. Chick \& J. L. Vincent (Eds.). Proceedings of the 29th PME International Conference, 3 , 281-288.

Marshall, S.P. (1993). Assessment of rational number understanding: A schema-based approach, in T.P. Carpenter, E. Fennema \& T.A. Romberg (Eds.), Rational Numbers: An Integration of Research, (pp. 261-288) Lawrence Erlbaum Associates, New Jersey.

Milinković, J. (2007). Methodological aspects of the introduction to probability and statistics. Belgrade: Faculty of Pedagogy.

Mrdja, M., Crvenković, S. \& Milovanovic, J. (2015). The increase in efficiency of interactive learning of mathematics through the implementation of mini exemplary teaching, IMVI Open Mathematical Education Notes, 5(2): 87-99.

Petrovic, N., Mrdja, M. \& Lazic, B. (2011). Models of differentiated interactive classroom teaching of mathematics. Norma, 15(2): 211-228.

Pitta-Pantazi, D., Gray, E. M. \& Christou, C. (2004). Elementary school students' mental representations of fractions. In M. J. Hoines \& A. D. Fuglestad (Eds.). Proceedings of the 28th PME International Conference, 4, 41-48.

Prediger, S. (2013). Focussing structural relations in the bar board - a design research study for fostering all students' conceptual understanding of fractions. In B. Ubuz, C. Haser \& M. A. Mariotti (Eds.), Proceedings of the 8th Congress of the European Society for Research in mathematics Education, Antalya, 343-352. 
Rasmussen, P. (2004). Towards flexible differentiation in higher education?: recent changes in Danish higher education, In Fägerlind, I. and Strömqvist, G. (Eds.), Reforming higher education in the Nordic countries studies of change in Denmark, Finland, Iceland, Norway and Sweden, International Institute for Educational Planning, Paris.

Santos, D.A. (2008). Andragogic propaedeutic mathematics, Available online at: http://www.freemathtexts.org/Santos/PDF/Arithmetic(2008).pdf.

Schon, D.A. (1963). Invention and the evolution of ideas. London: Social science paperbacks.

Shulman, L. S. (2005). Signature pedagogy in the professions. Daedalus, 134(3): 52-59.

Siegler, R.S., Thompson, C.A. \& Schneider, M. (2011). An integrated theory of whole number and fractions development. Cognitive Psychology, 62(4): 273-296.

Siegler, R.S., Fazio, L.K., Bailey, D.H. \& Zhou, X. (2013). Fractions: the new frontier for theories of numerical development, Trends in Cognitive Sciences, 17(1): 13-19.

Small, M. (2009). Teaching to the Big Ideas K-3, Mathfocus K-3, Nelson.

Smith, J. P. (2002). The development of students' knowledge of fractions and ratios. In Litwiller, B. ve Bright, G. (Eds). Making Sense of Fractions, Ratios, and Proportions: Yearbook. P. 1-2. NCTM: Reston, VA.

Steffe, L.P. \& Olive, J. (2009). Children's Fractional Knowledge. New York: Springer.

Strang, T. (1990). The fraction-concept in comprehensive school at grade-levels 3-6 in Finland. In G. Booker, P. Cobb \& T. N. Mendicuti (Eds.), Proceedings of the $14^{\text {th }}$ PME International Conference, 3, 75-80.

Tennyson, R. D. \& Park, O. (1980). The teaching concept: A review of instructional design research literature. Review of Educational Research, 50(1): 55-70.

Torbeyns, J., Schneider, M., Xin, Z. \& Siegler, R.S. (2014). Bridging the gap: Fraction understanding is central to mathematics achievement in students from three different continents. Learning and Instruction, 37(1): 513.

Vasilyev, N.S. \& Gromyko, V.I. (2015). Propaedeutic Mathematical courses in the context of continuous learning, [Н.С. Васильев, В.И. Громыко, Пропедевтические курсы математики в условиях непрерывного образования. Гуманитарный вестник, МГТУ им. Н.Э. Баумана, 2(28):1-17]

Vygotsky, L.S. (1987). Thinking and Speech. In R.W. Rieber and A.S. Carton (Eds.), The collected works of L.S. Vygotsky (vol. 1, pp.39-285). New York: Plenum Press.

Watanabe, T. (2006). Teaching and learning of fractions: A Japanese perceptive, Teaching Children Mathematics, 12(7), 368-372.

Watanabe, T. (2012). Thinking about learning and teaching sequences for the addition and subtraction of fractions. In C. Bruce (Chair), Think Tank on the Addition and Subtraction of Fractions. Think Tank conducted in Barrie, Ontario.

Wittmann, G. (2013). The consistency of students' error patterns in solving computationalproblems with fractions. In B. Ubuz, C. Haser \& M. A. Mariotti (Eds.), Proceedings of the 8th Congress of the European Society for Research in mathematics Education, Antalya, 393-402.

Zech, F. (1999). Grundkurs Mathematikdidaktik - Theoretische und praktische Anleitungen für das Lehren und Lernen von Mathematik, Beltz Verlag - Weinheim und Basel. 